\title{
Identifying World Types to Deliver Gameful Experiences for Sustainable Learning in the Metaverse
}

\author{
Sungjin Park ${ }^{1}$ and Sangkyun Kim ${ }^{2, *}$
}

1 Institute for Information and Communication, Ajou University, Suwon 16499, Korea; say121290@ajou.ac.kr

2 Department of Industrial Engineering, Kangwon National University, Chuncheon 24341, Korea

* Correspondence: saviour@kangwon.ac.kr

Citation: Park, S.; Kim, S. Identifying World Types to Deliver Gameful

Experiences for Sustainable Learning in the Metaverse. Sustainability 2022, 14, 1361. https://doi.org/10.3390/ su14031361

Academic Editor: Sara Catalán Gil

Received: 29 December 2021

Accepted: 22 January 2022

Published: 25 January 2022

Publisher's Note: MDPI stays neutral with regard to jurisdictional claims in published maps and institutional affiliations.

Copyright: (C) 2022 by the authors. Licensee MDPI, Basel, Switzerland. This article is an open access article distributed under the terms and conditions of the Creative Commons Attribution (CC BY) license (https:// creativecommons.org/licenses/by/ $4.0 /)$.

\begin{abstract}
The metaverse is expected to turn imagination into reality through the convergence of various technologies and should be considered as a medium for sustainable education, free from the constraints of time and space. The purpose of this study was to identify world types in the metaverse to deliver a gameful experience to users. The relationship between gameful experience and learning motivation was examined by analyzing previous studies. Furthermore, the metaverse platforms were confirmed as virtual worlds using the metaverse classification. This study employed a bottom-up approach based on real cases to identify world types that can be used for metaverse-based education. Survival, maze, multi-choice, racing/jump, and escape room world types were identified. The results of this study can be used to provide equal educational opportunities to learners by creating innovative educational environments. This is expected to enable the achievement of the fourth sustainable development goal.
\end{abstract}

Keywords: gamification; gameful experience; metaverse; generation Z; sustainable learning

\section{Introduction}

The COVID-19 pandemic has accelerated technological advancement. Due to limitations on offline activities, people have been spending more and more time online. Thereby, methods of delivering an online experience similar to the offline world are being explored. Previously, the metaverse only talked about the online virtual world, but today, in the postpandemic world, it has become a medium that connects the on/offline realms. centering on augmented reality and virtual reality technology [1].

The main users of metaverse are the members of Generation Z. Individuals born after 1995, who have characteristics different from the previous generations are called Generation Z. Researchers have focused on this generation's characteristic of favoring gameful experiences as they grew up at a time when PC and mobile technologies with games were evolving [2]. Gameful experience is related to gamification (defined in Figure 1); it describes a technique that positively affects user participation and motivation by applying game elements such as points, badges, levels, and leaderboards in a non-game context, including education, business, and health care [3]. Gamification in education induces the effects of learner motivation, learning participation, and attitude improvement through these game elements [4]. Furthermore, gameful experience is described as an experience similar to playing a game but in a non-game context that is interpreted differently from a game-like experience. It can be said that an individual has a gameful experience when they have an experience of playing a game unintentionally [5,6]. 


\section{Gamification}

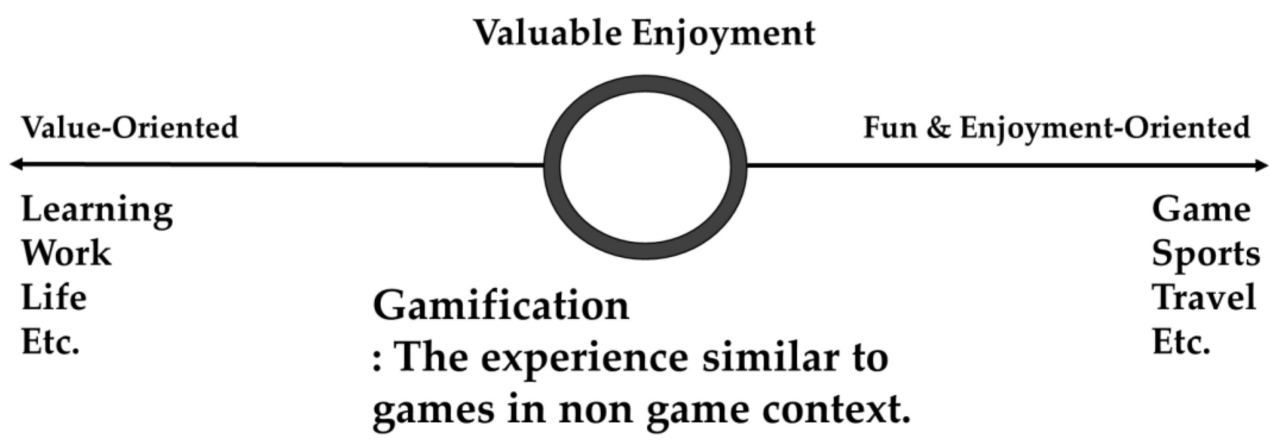

Figure 1. Definition of gamification [4].

Since the beginning of the COVID-19 pandemic, problems with online education activities have started to become evident, such as in cases in which learners could not properly participate in the class or the instructor did not conduct the class appropriately. As a result, there has been a decline in the quality of education due to the lack of experience with online video conferencing programs or poor interaction between learners in online video-based classes [7]. Online learning without interaction was not significantly different from traditional learning in the past or was found to have a negative effect on learners learning motivation and learning attitude [8].

Accordingly, to solve the problems of online learning, a method of delivering value based on gameful experiences in the metaverse has been explored. An example of gameful experiences in the metaverse being used for education is the use of metaverse to train public servants in South Korea (Figure 2). According to Song [9], a virtual education site was designed on a metaverse platform, and gamification was implemented to predict future social problems such as climate change, low fertility, and aging. The platform then allowed public servants to design a virtual smart city in order to solve these problems.

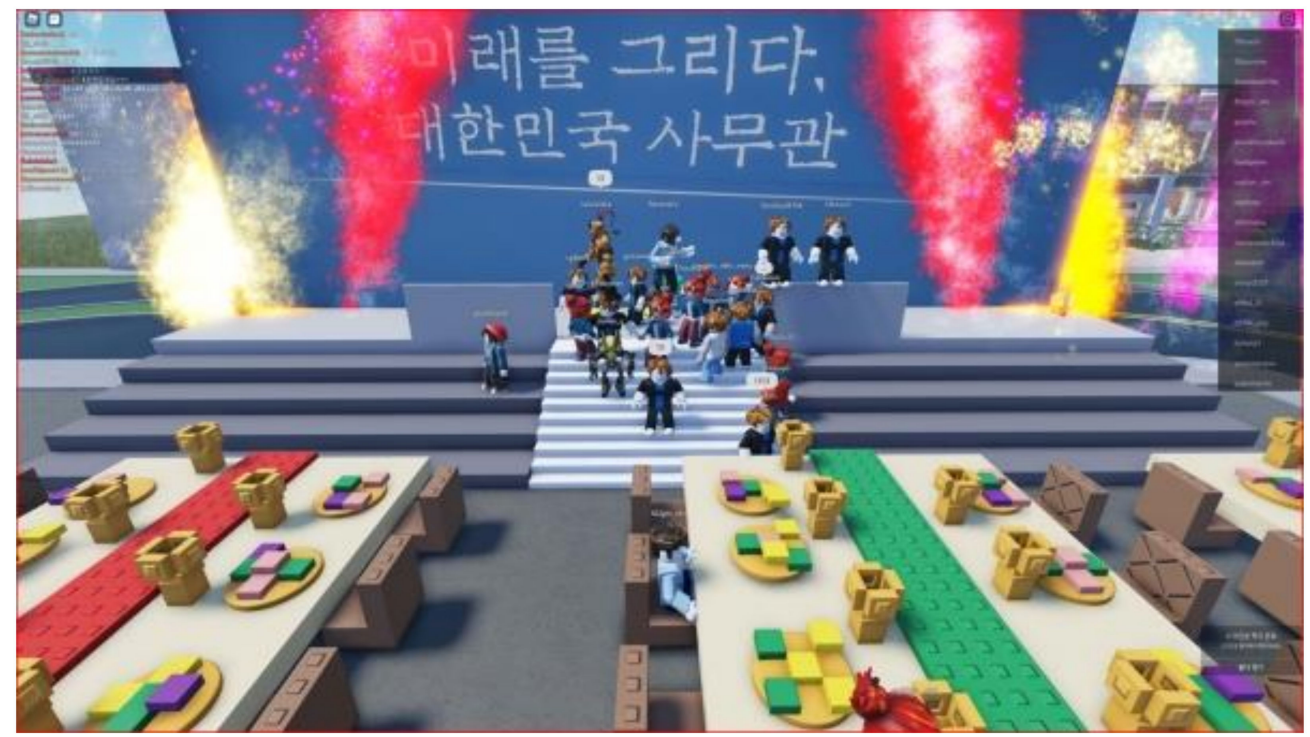

Figure 2. A case study on the gamification in the metaverse for educating public officials [8].

This study focused on identifying world types with the potential to deliver gameful experiences in the metaverse; real users access worlds in the metaverse where they interact with other users. The derived world types are expected to be useful for the provision of 
equal educational opportunities for learners deprived as a result of their environment. The study of metaverse world design for sustainable learning is imperative, as most previous world designs were based on the experiences of educators, rather than those of students active in the real metaverse. In this study, the effect of game experience on learning was analyzed based on the three threads of experience identified by Kim [10]. World types that can deliver a gameful experience in the metaverse were identified by collecting cases from the real metaverse.

\section{Literature Review of Metaverse, Experience, and Gameful Experience}

\subsection{Metaverse}

Metaverse combines "meta," meaning virtual and transcendent, and "verse," referring to the world and universe. The word first appeared in the novel Snow Crash published in 1992 [11]. Metaverse was being developed based on virtual reality before the COVID-19 pandemic, but attracted renewed attention once it struck to meet the limitations of external activities and individual needs. It is a rapidly expanding concept.

Acceleration Studies Foundation (ASF), a non-profit technology research organization, published a metaverse road map in 2007 and presented four classification criteria for metaverse (Figure 3). According to ASF [12], the $x$-axis in Figure 3 indicates the direction of technology while implementing the metaverse. This distinguishes whether it is a technology that projects information from the real world in which metaverse users live or a technology that is implemented by focusing on the identity of the user or object, and their inner world. The $y$-axis indicates whether the technology improves the quality of lives by adding new functions in the real world of users or creates new values by implementing realistically impossible things in a completely new virtual world.

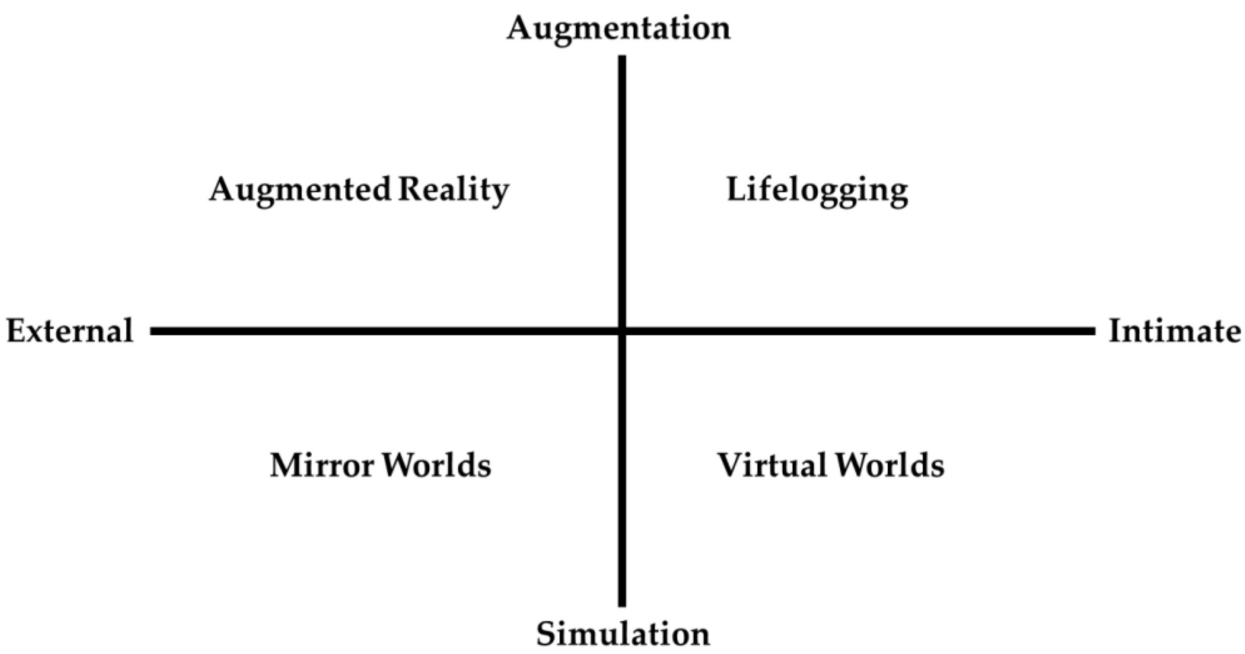

Figure 3. Types of Metaverse [12].

- Augmented Reality: A method of projecting information using a device in a way such that it provides additional information using a smartphone or smart device in the real world.

- Mirror Worlds: A space that provides new information or activities to users by creating a space identical to the real world in the virtual world.

- Virtual Worlds: A virtual space where users can move their avatars based on 3D graphics.

- Lifelogging: A virtual space in which data and actions occurring in reality are transferred to the virtual world as they are.

Duan et al. [11] implemented a metaverse in a university campus by creating a virtual space using the metaverse platform to examine the behavior of students engaged in it. As a result, a simple economic system or democratic activity was guaranteed even within the metaverse. 
According to the classification by ASF [12], representative metaverse platforms including Zepeto, Roblox, Gather.town, and Fortnite can be classified as "virtual worlds" (Figure 4). The four metaverse platforms provide a user experience based on a 3D graphic environment and a studio program, which serves as a world development tool. Users create their own virtual playgrounds by customizing the virtual world using the studio tool.

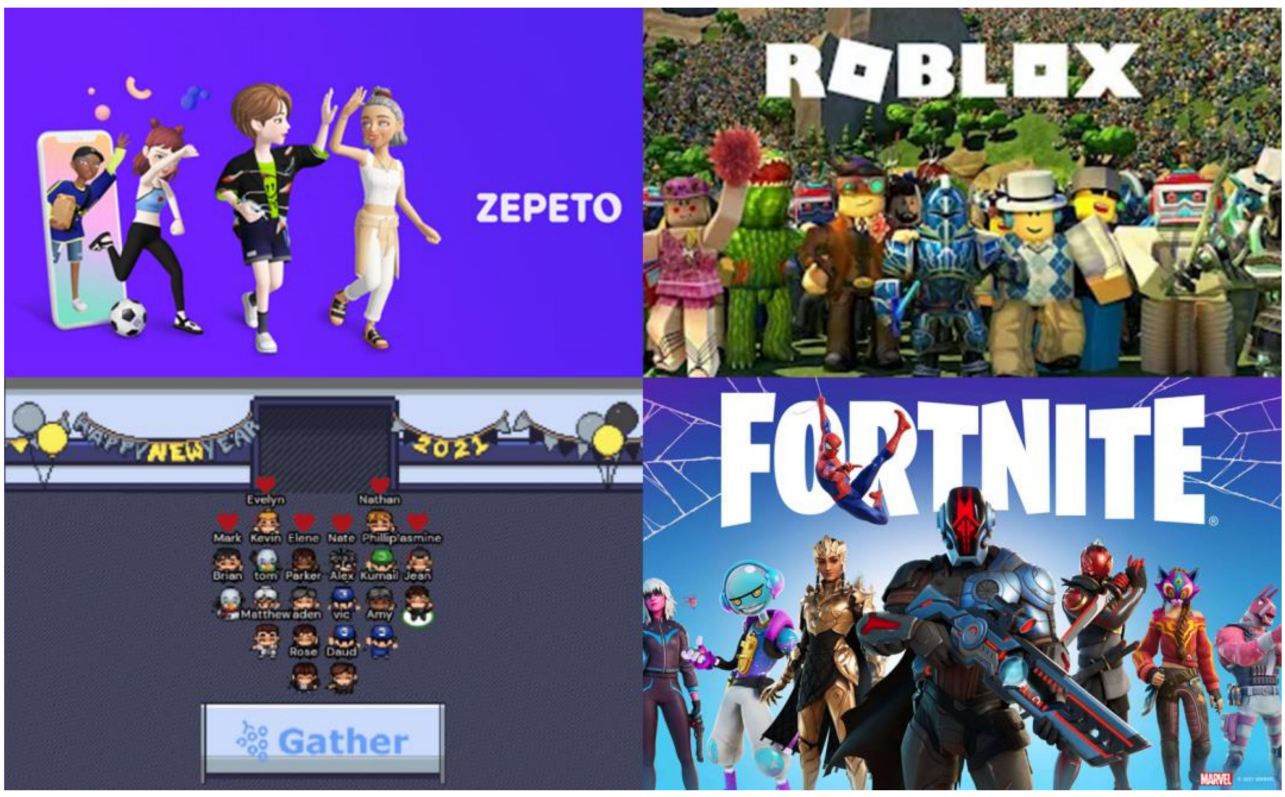

Figure 4. Screenshots of major metaverse platforms.

The four metaverse platforms identified in Figure 4 were found to have a large number of users globally. There are cases of private companies using the metaverse to promote their products or services, as well as celebrity performances. As such, the most user-accessible form of metaverse is currently the virtual world.

\subsection{Experience}

Experience is not a clearly defined word, but it can be understood in a specific context. The concept is used in various fields such as education, sociology, and management. It originates from certain types of mental consciousness, such as perception and sensation which provides an individual with the awareness of being present [13]. If the existing academic definition of experience is approached broadly, it includes events caused by various mental states such as dreaming and thinking [13]. Therefore, it is difficult to define experience, and various perspectives in each field explain it differently [10].

Kim [10] used three threads to classify individual experiences by analyzing previous studies that approached experience philosophically. Kim presented a framework for categorizing personal experiences from various perspectives, such as the experience gained through personal sensory experience and interaction and the experience of the physical space in which the individual is located (Figure 5). 


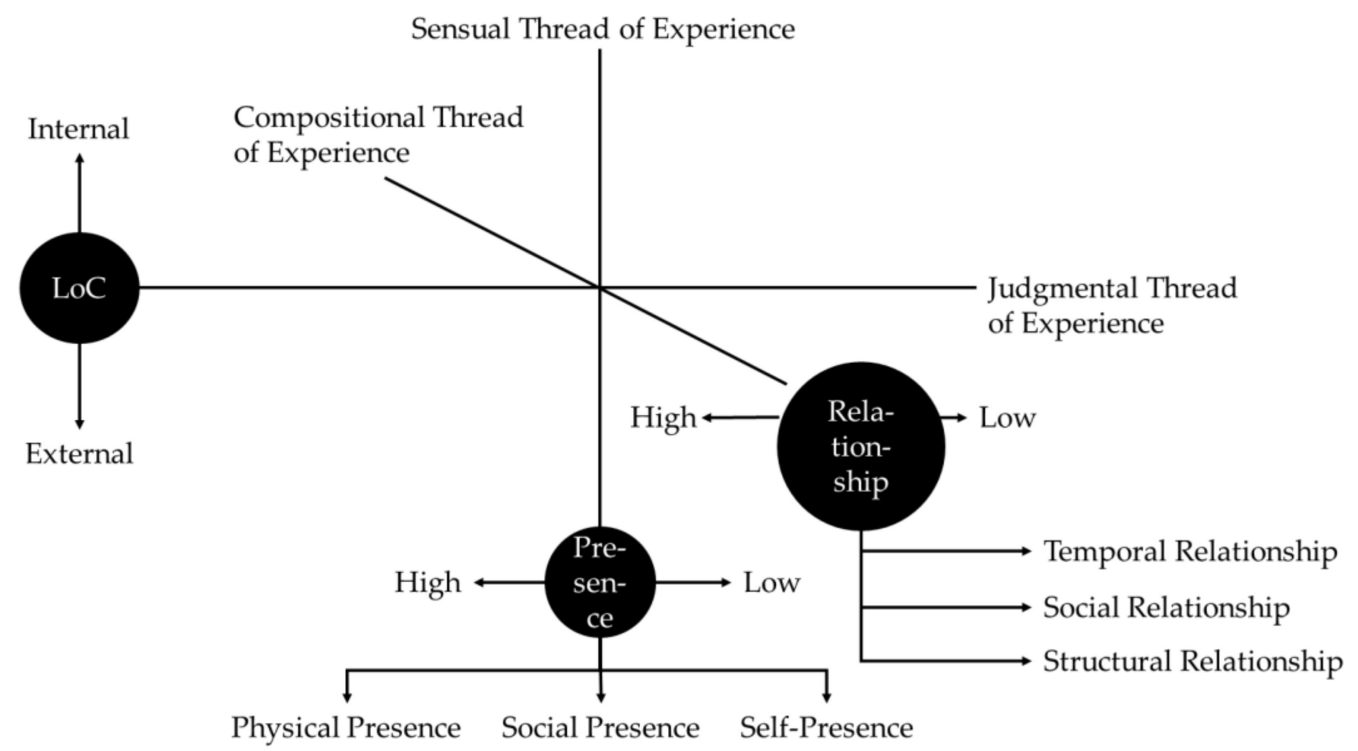

Figure 5. Kim's [5] threads of experience.

The first criterion is the sensual thread of experience that indicates an experience that can be felt using the human senses. It is a concrete and practical experience that responds to external stimuli. The characteristic of the sensual thread of experience is that it consists of a sense of presence (SoP), which is a psychological state that makes an individual have the feeling of "being there". Accordingly, when an individual has a sensual thread of experience, its degree felt by an individual varies according to whether the presence is high or low.

- Physical Presence: This is a state in which one can feel the existence of a specific target that can be physically experienced. For instance, how realistic the equipment worn by the character or an environment in the virtual world feels can be expressed to give a sense of the physical presence.

- Social Presence: This is the element that one experiences when they recognize a connection with another person. Conversation with others through online social networking services corresponds to social presence.

- Self-presence: This is an experience that allows an individual to feel their presence in a specific situation or environment. It is an element the individual can feel when they interact with something else or exercise influence.

The second criterion is the judgmental thread of experience. This refers to all experiences that occur when judgments made by an individual affect not only internal emotions but also the external environment. The key element of the judgmental thread of experience is locus of causality (LoC). Locus of causality is an extended concept of locus of control used in psychology and organizational behavior. It refers to the qualitative degree to which one can exercise influence by controlling a specific event. Locus of causality is divided into the following.

- Intrinsic LoC: This refers to a situation in which an individual directly participates and has direct control over the surrounding environment, members, or constituents.

- Extrinsic LoC: This is an element that cannot be directly controlled by the surrounding situation, members, or components, but is controlled by other people or systems, or is an element that can be felt on using something that has been completed.

The third criterion is the compositional thread of experience. The compositional thread of experience refers to the elements that make up the experience. For instance, friends who went fishing together and the equipment used, or friends who exercised together on the school yard and the ball, are elements of the compositional thread of experience. The 
compositional thread of experience is divided into cohesion of time, social relationship, and structural relationship based on the relationship between experience elements.

- Cohesion of temporal relationship: This refers to the structure of a completed experience in which the elements are arranged in a time series order. It is a key element in experiences that are universally organized in a sequence of actions and outcomes.

- Cohesion of social relationship: This is an experience structure in which an individual and others are socially connected in an experience.

- Cohesion of structural relationship: This refers to the structural relationship that is formed not only with people but also with various relational objects such as products, services, and structures in experience.

\subsection{Gameful Experience and Motivation}

When a game-like experience is created using game elements such as game mechanics and game rules in a non-game context, it is called a gameful experience [14]. A gameful experience delivers enjoyment, absorption, creative thinking, absence of negative affect, activation, and dominance to users, thus increasing user loyalty and participation [14]. Furthermore, it is not considered a gaming experience because it creates a game-like experience but in a non-game context, while gaming experience refers to what an individual feels after playing an actual game [6].

Gameful experience is considered to be effective for education because of the following five attributes of experience it promotes, as suggested by Dewey [15], including continuity, interaction, interest, growth, and educational experience. Figure 6 illustrates the basic learning structure in education when gamification is applied [16].

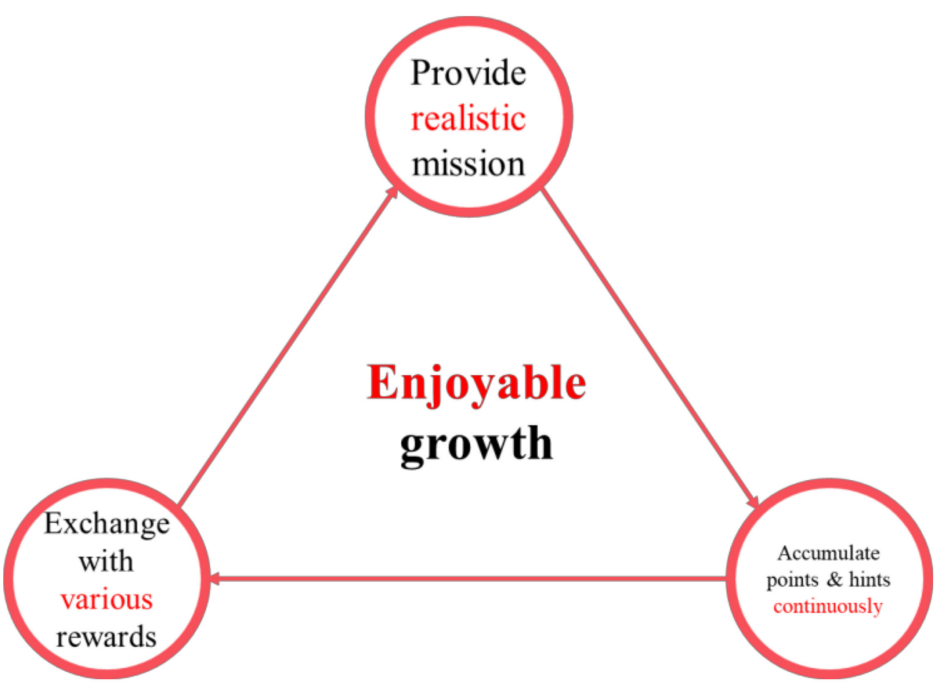

Figure 6. Basic structure in gamification of learning [16].

For sustainable learning, the instructor provides learners with missions/quests continuously for a fixed or variable duration. The learners master or expand the knowledge they have accumulated while solving the missions/quests they face. At the same time, instructors set learning goals through missions/quests [17]. The process of the learners solving the mission/quest is not a simple "repetition" of knowledge but a continuous expansion of knowledge. The learner who successfully solves the mission/quest receives a reward from the instructor. The reward has various forms such as points or privileges and benefits that help other learning activities. In the point, badge, and leaderboard (PBL) system, when learners fulfill a mission/quest, they receive points, and the points are displayed on the leaderboard, promoting the learner's learning motivation. In addition to the PBL system, other types of games such as the room escape game and big game provide other rewards, facilitating learning activities. The learner exchanges the rewards obtained 
by fulfilling missions/quests for various practical rewards. The reward is exchanged by the learner for benefits, rights, and virtual goods, which directly or indirectly affects learning activities. The exchanged reward induces interaction with the instructor or other learners and exerts influence.

Classcraft (Figure 7) is presented as an example for Figure 6. Classcraft is a learning operation platform where individual students can create their own avatar and choose their own profession. Warrior, wizard, and healer are representative occupations. Learners earn points each time they solve the problems presented by the instructor. The points are used to attain unique skills. Each occupation has its own unique skills. Examples of unique skills include controlling air conditioning, eating in class, and nullifying one tardy moment. They do not violate school rules and are enough of a privilege to exert an appropriate level of influence on other learners.

\section{Learn powers}

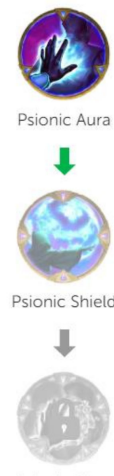

Psionic Flare

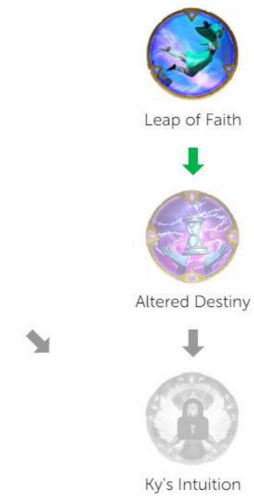

You have 15 औ

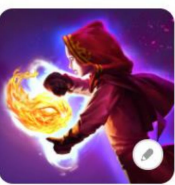

Elemental Affinity

-20 AP

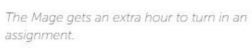

LEARN FOR 1 *

Figure 7. Classcraft's skill cases.

The instructor constructs a learning cycle structure for the learner's sustainable learning so that the learner is continuously drawn to learning activities. In addition, in this process, the learning experience is expanded by inducing interactions between learners, between learners and teachers, and between learners and the educational environment. The game rules or game mechanics set by the instructor arouse the interest of the learners. In particular, the game mechanics induce affordance by stimulating six individual factors in the learners that induce sustainable learning [18]. The six factors are:

- Conscientiousness: An individual factor that actively plans or organizes tasks and draws results.

- Agreeableness: An individual factor that helps others or expects to receive help from others.

- Neuroticism: An individual factor related to inner self management, such as fear, sadness, embarrassment, distrust, or difficulty in managing stress.

- Emotional stability: An individual component that is the opposite of neuroticism.

- Extraversion: An individual factor that promotes finding new opportunities or interests.

- Imagination/Openness: An individual factor that helps in inventing new and original ideas, having unconventional values, or questioning authority.

The learner's sustainable educational growth is achieved because the gameful experience is expanded into the learning experience [19]. Through self-reflection on what the individual felt during learning activities, interactions with other learners, the instructor, and the educational environment, and their own values and growth, the learner feels the experience of "learning" based on the experience elements of Kim [10]. The gameful experience extends to the learning experience and has a positive effect on the learner's learning motivation. 


\section{World Type Identification and Experience Factor Analysis}

In this study, real cases were collected to identify world types that stimulate learning motivation by delivering gameful experience in the virtual world metaverse. World cases developed by Zepeto, Roblox, Gather.town, and Fortnite were collected. To assess the case, the discussed metaverse platform application was installed, and the world was experienced directly. If a metaverse world could not be entered, online resources such as news articles were used to analyze users' experience. The adopted research method followed a bottom-up process familiar in the field of software development, starting from the most basic concept or definition, identifying similar patterns and values, and finding higher-order concepts from the derived results [20]. Among the collected cases, the current study intensively analyzed cases containing both gameful experiences and educational value. As a result, five world types were identified.

- Survival World: A world in which one competes with other users for knowledge until the last survivor wins.

- Maze World: Among the elements that make up the world, the maze takes up a large proportion. A world that transmits knowledge in the process of forcing the choice of a maze wall or forked road.

- Multi-choice World: A rule-based world where the user who finds the correct answer among options, such as OX quiz, spot the difference, and solve a puzzle, and the user with the most correct answers wins.

- Racing/Jump World: A world in which the user who reaches the final point by moving their avatar wins.

- Escape Room World: The user needs to arrive at the final escape point first to win. A world that hides hints for escaping the current space, and requires user knowledge and hints to solve problems.

The five virtual world types identified in this study stimulate learning motivation by delivering a gameful experience to users based on the basic structure of gamification suggested by Kim et al. [4]. First, the five virtual world types provide users with victory conditions and missions/quests. Victory conditions are surviving to the end, getting the highest score, coming first in a race, reaching the top first, and escaping the room. The missions/quests provided to users to achieve the victory conditions are giving correct answers, finding hidden hints, getting points, and choosing the right path at a fork in the road. The users acquire "game-like experience" according to the basic structure of gamification and acquire knowledge in the process of applying it to understand the virtual world or game rules. In this process, the users gain various experiences based on the three threads of experience suggested by Kim [10] and the game-like experience starts to have a positive effect on the learning motivation.

\subsection{Survival World}

The survival world is an environment in which one competes until only one survivor remains within a limited time. The survival world is based on strict game rules. The user has to compete for knowledge with other users until the last person emerges the winner. In the existing metaverse platform, the game was carried out in the same way as a first-person shooter game and a game for survival in an isolated area. In the educational survival world, users must compete with other users for knowledge to win after obtaining information from all over the world or improving their level of common sense. Conversely, when the user gives an incorrect answer or makes a wrong choice, the user is eliminated from the game and can no longer participate.

An example survival world is a world created collaboratively by Korea Tourism Organization and the metaverse platform, Roblox (Figure 8). In the corresponding world created, a survival game was carried out with questions about Gangneung, South Korea drawing from the Korean drama, Squid Game. The game world had recorded 70,000 cumulative visitors by December 2021. 


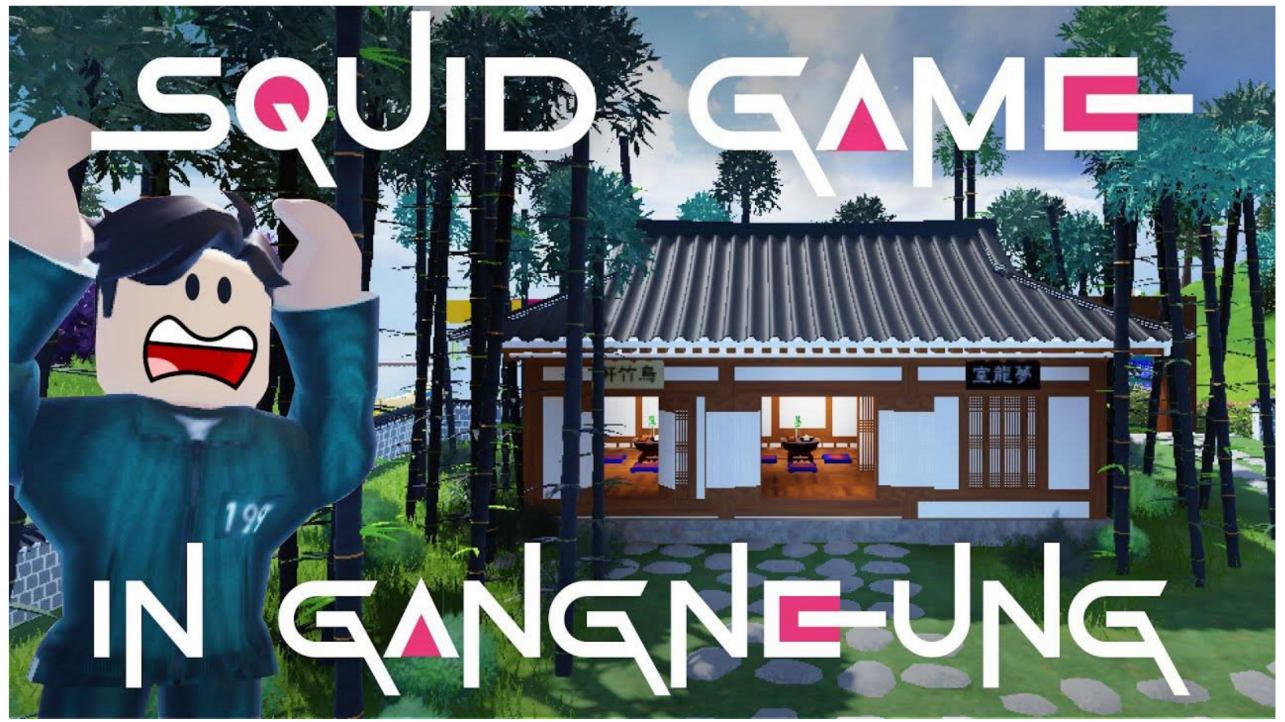

Figure 8. Survival world created by Korea Tourism Organization.

The key word of the survival world is competition. One is eliminated or unable to participate anymore when one loses in the competition against other users. Thereby, sensory experience is obtained based on a high sense of presence centered on self-presence. In addition, the user needs to interact with oneself (internal LoC) or with other people or environmental factors (external LoC) while competing with other users. Since the survival world provides a competitive situation, the degree of cohesion with the components of experience increases mainly in temporal and social relationships. Based on the user's experience, a gameful experience is provided by the survival world, and it stimulates the learner's motivation for sustainable learning.

\subsection{Maze World}

The maze world is in environment that has mazes all over the world or more than half of the world is made up of mazes. The user is guided to the starting point and has to explore the world to get out of the maze. Although the user is not eliminated in the middle, the user cannot escape if they fail to utilize the information written on the maze wall.

Figure 9 illustrates "GUCCI Villa Mansion" created jointly by the metaverse platform Zepeto and luxury brand, GUCCI. Products of the brand are displayed throughout the virtual space through statues and photos of models. The user explores the space to discover new spots or take pictures of their avatar. There is no restriction on the users, but they are exposed to GUCCI-related information on walking around the maze and buildings.

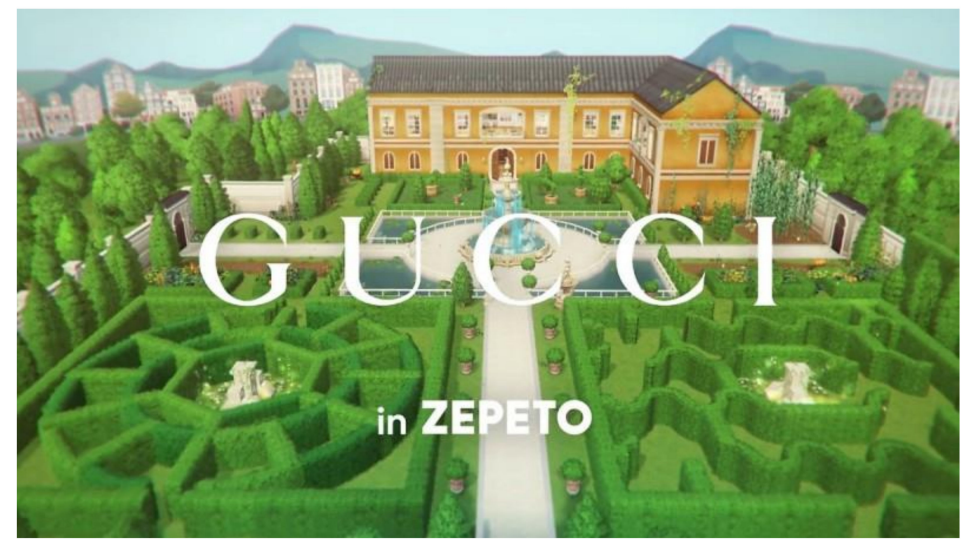

Figure 9. Maze world example made by GUCCI (Captured by GUCCI Hompage: https: / / www. facebook.com/watch/?v=3606419949582197, accessed on 1 December 2021). 
The key word of the maze world is exploration. Users enjoy the process of exploring the surroundings and finding the right path. In the maze world, there is more interaction with walls and other objects present in the world than with other users since information about escaping the maze is provided within the world. A high level of sensual experience for situational judgment is felt by the users because they have to sensibly find a way to escape from the maze. Therefore, based on self-presence, the users adequately experience internal LoC and external LoC. Lastly, the experience revolves around structural relationships since the maze world interacts with the maze installed in the world.

\subsection{Multi-Choice Game World}

The multi-choice game world is an environment where users can participate directly by implementing components and rules in the game such as an OX game and finding the wrong answers in a virtual world. In the multi-choice game world, users interact with the structures in the virtual world structures, move according to the moderator who controls the entire activity, or act according to the rules notified in the world. For instance, when taking an OX quiz, the moderator provides a quiz, the user moves the avatar on the floor with OX on it, or the posts at the entrance to the maze fall under the rules of the game. Users gain knowledge by recognizing correct and incorrect answers when they have to choose a path to obtain new information from the quiz presented by the moderator or to escape the maze. Furthermore, in the multi-choice game world, there is no concept of "failure," and even if the user chooses the wrong answer, they can try again.

Figure 10 is an example of the OX quiz map and multiple-choice game developed on the metaverse platform, Gather.town. The user is placed in a virtual space created by the world designer and must choose the correct answer according to the guidance and explanation provided by the moderator. It is a structure in which the more correct answers a user gets, the better rewards or recognition they receive from other users.

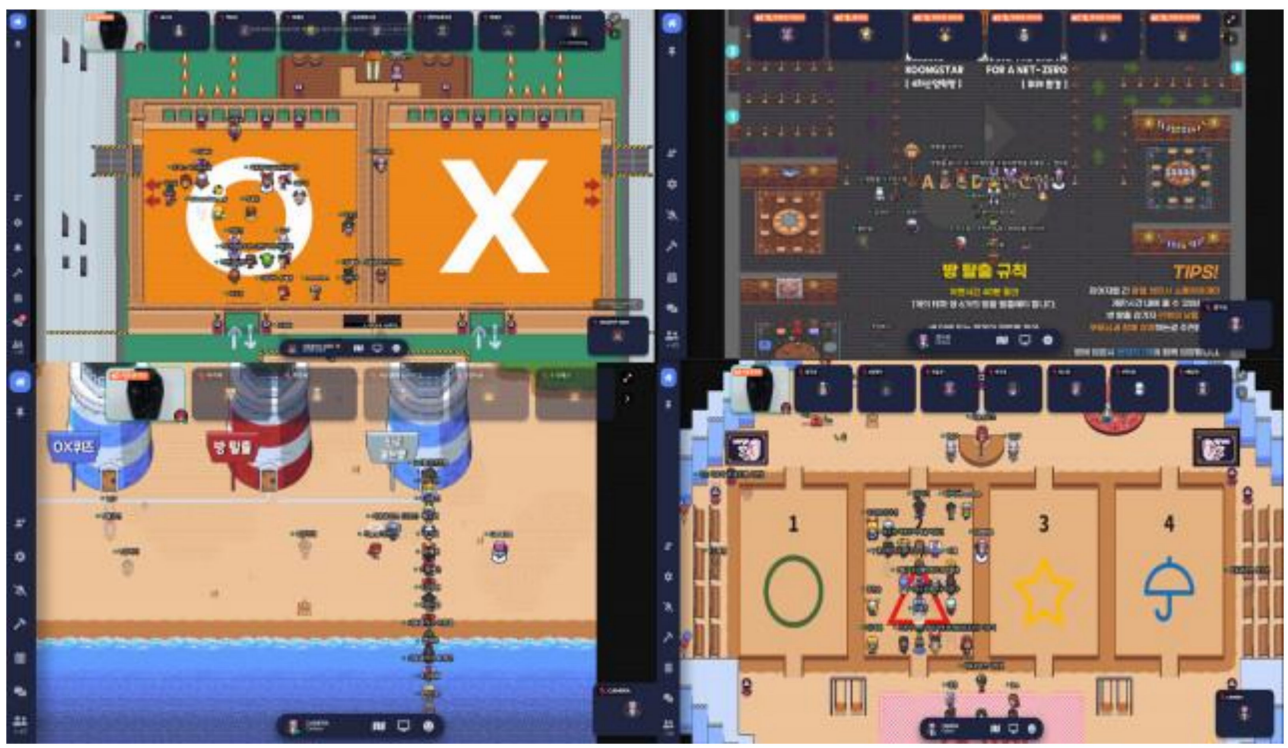

Figure 10. OX game or multi-choice game world made by Seoul Eunpyeong Career Center for Youth \& Future, Korea.

In the multi-choice game world, the users experience a sense of reality centered on self-presence and social presence. Users with a high level of existing knowledge experience self-presence, but learners with a relatively low level of knowledge acquire points through solidarity with other learners. In the multi-choice game world, the users experience a high level of external LoC because their status is determined by the moderator who runs the entire game and the correct answers. They experience temporal and social relationships 
since the experience takes place in a sequential process and interaction between different users occurs.

\subsection{Racing/Jump World}

The racing/jump world is a rules-based virtual world in which the user wins by moving their avatar to reach the end first. The racing/jump world maximizes competition between users. In the racing/jump world, users can experience events such as starting with the same conditions and acquiring items during the game to move faster or take shortcuts. The racing/jump world delivers information the developers want to convey to users by applying it to the background of the virtual world such as the path and the footsteps. This information transfer method uses passive learning theory from the field of marketing. The world designer intentionally presents the information repeatedly. In this process, users do not pay much attention to the information/message conveyed by the world and perceive it as low involvement, but passively remember it due to repeated exposure [21].

Figure 11 shows the Galaxy world jointly created by Samsung and ZEPETO. The user controls their avatar and wins if they arrive at the destination before other users. The world type in which the avatar moves, the shape of the terrain features, such as the spacing or height of the footrest, is not common, and the avatar must be moved in consideration of the surrounding terrain. Thus, users' physical skills (a collective term for sensory factors related to body movement, such as body reaction speed, reflexes, and body vision) and neurological skills (a collective term for mental factors such as situational judgment, common sense, strategic choices, and decisions) are required.

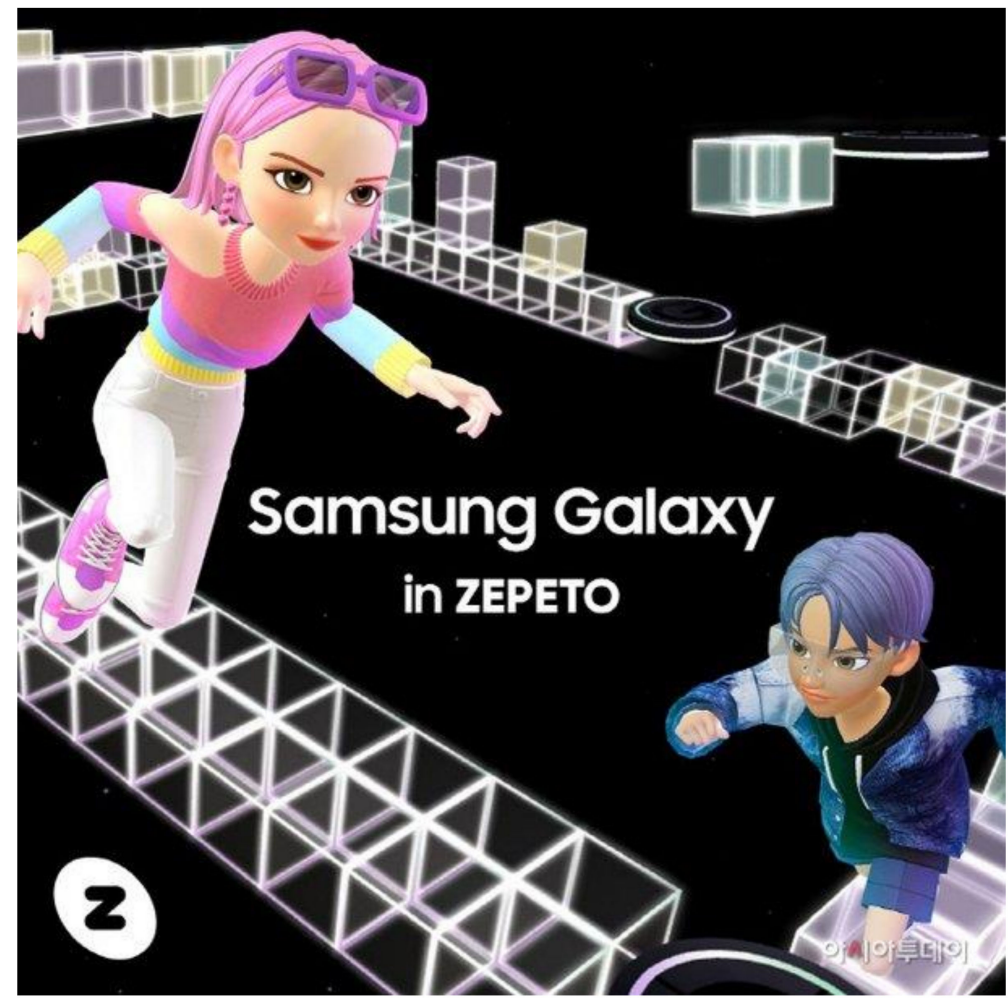

Figure 11. Jump world made by Samsung.

In a racing/jump world, competition with other users is important, but physical skills are the most important to successfully fulfill the victory conditions and missions/quests. The ability to handle the avatar compared to other users, the reflexes, and the body's reaction speed to respond when one's avatar is in trouble are directly related to victory or defeat. Accordingly, the users experience a high level of physical presence. Moreover, they experience a high level of internal LoC since they have to make decisions and move 
forward faster than other users. Lastly, the objectives of the world that are directly involved in achieving victory are the structures. The degree of one's ability is determined by whether the structure is difficult or easy. Because of this, the users feel an experience centered on structural relationships.

\subsection{Escape Room World}

The escape room world is a virtual world in which an individual or two or more users find hidden hints in a virtual space, move to the next area or next space, and whoever escapes to the final point first wins. The escape room world method has been used since before the metaverse. The learner is locked in a specific space (e.g., classroom or gym), and hints are hidden in the equipment placed in the space (e.g., locker, basketball hoop, TV monitor, etc.). The learner solves the problems by finding the hints hidden in the space, enters the final correct answer obtained through problem solving, and escapes the room [22]. There are no game components or complete rules, and the escape room can reflect the characteristics of all four worlds mentioned above. Thus, this world demands creativity from the designer. The escape room game has a positive effect on the learner's problemsolving ability and creativity, and soft skills such as leadership and communication [22,23].

Figure 12 shows an escape room world on Gather.town developed for the gamification lecture in the second semester of 2021 of University A located in Korea. The purpose of the world is to provide a brief rest and job-related information to people who are stressed out because of looking for a job. The user reads a brief notice in the beginning of the world space, and then collects the information required for escaping. In the process of collecting information, the user moves to another space. During this process, the user experiences stability and relaxation because of the world background, background music, and embedded videos. The hints obtained provide information on how to fill out applications or interview techniques necessary for finding employment.

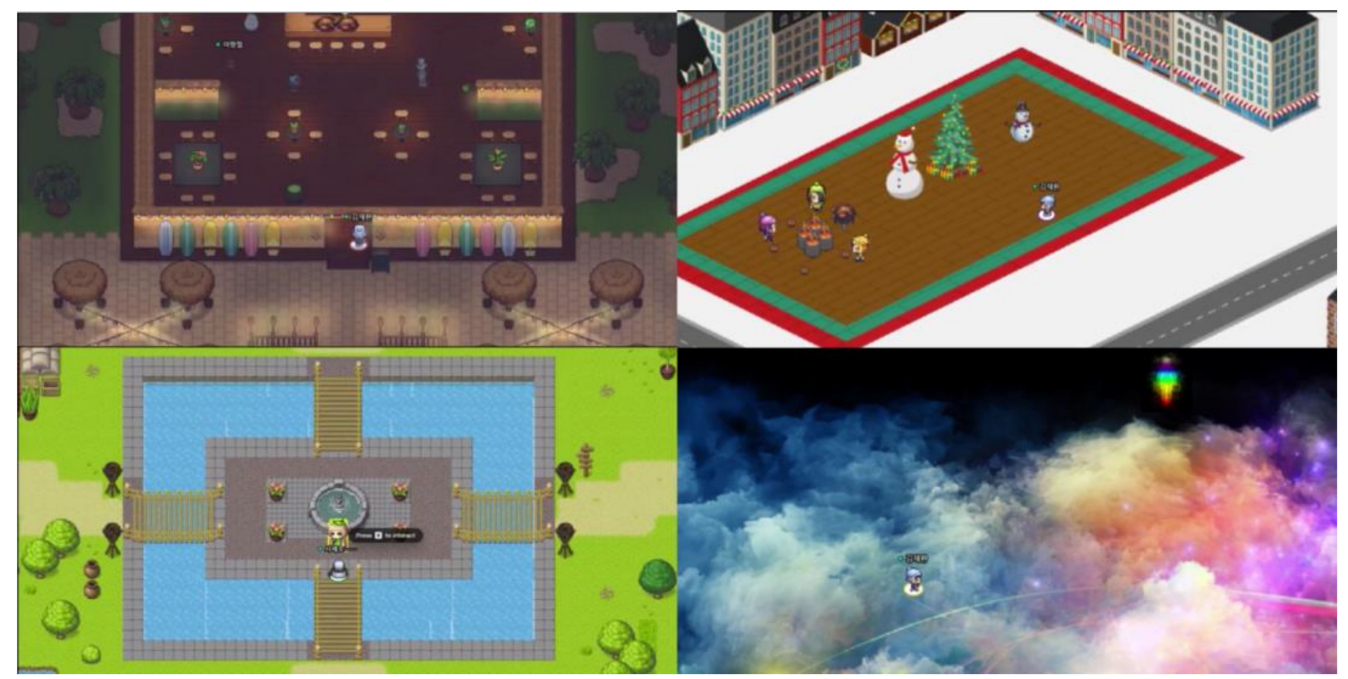

Figure 12. Escape room world.

Lastly, the escape room world enables the users to experience all the elements of experience mentioned by Kim [10]. The users find the hint hidden in the map to escape the room where the avatar is located. The process of finding a hint can be developed in a multi-choice form or in various forms such as a maze escape. Thus, a sense of reality experience is possible depending on the type of mission/quest the user faces. Moreover, when the user has to use knowledge or skills to solve the missions/quests, they feel the internal LoC. When solving missions/quests tailored to the surrounding environment or storyline in which the user is placed, the user experiences external LoC. Lastly, the user gains various experiences by arranging the hints collected for escaping in a chronological 
order to get the final correct answer, collaborating with other users to get the correct answer, and acquiring hints present in the world background.

\section{Discussion \& Conclusions}

To ensure sustainable educational activities for users in the metaverse, this study presented the five world types that can be used for creating gameful experiences. Previous studies were analyzed to understand gameful experience and suggest world types. The elements that comprised the experience were examined on the basis of Kim [10]'s three experience threads. The effects and principles of gameful experience on learning effects were explored.

To present the virtual world design framework and world types, this study focused on player-type research in previous studies. This is because player-type research is a theory derived from the behavioral patterns of players in real games. Moreover, this is because gamification can be maximized by delivering a customized gameful experience. As a result, survival, maze, multi-choice game, racing/jump, and escape room world types were identified as they promote user's interest in the object and the user's action range. The five virtual world types identified in this study are expected to be utilized in educational design created using the metaverse in the future. Many individuals from generation $\mathrm{Z}$ are already active in the metaverse. Studies have found that online education using Zoom or Google Meet is not very different from the existing traditional education methods. Education using gamified learning has attempted to break free of the limitations of traditional education methods such as existing offline education. To prevent future problems in offline education, gameful experience-based education in the metaverse should be actively considered.

From the perspective of using the metaverse for education, the five virtual world types identified in this study address one of the issues that needs to be considered during the education design stage. The metaverse suggests that the applicability of gameful experience to a user's activity space, and the gameful experience-based world, is expected to have a positive effect on a user's learning motivation.

This study expects that it will be possible to achieve the fourth goal of the sustainable development goals (SDGs) through the five identified world types. The fourth goal of the SDGs is to provide equal, equitable, and high-quality educational opportunities for all. Education has changed significantly due to the COVID-19 pandemic, but methods of satisfying both educators and learners are being explored. Among these methods, education using the metaverse has emerged as an alternative. Education using the metaverse is expected to be free from the constraints of time and space and provide equal opportunities to those who suffer due to physical problems and environments (e.g., alpine and disaster areas). By delivering a participatory educational experience centered on gameful experience, education using the metaverse can overcome the limitations of online education and build a sustainable educational environment [23].

The limitations of this study are as follows:

- $\quad$ Lack of world design methodology

- Absence of case analysis of the augmented reality (AR) world, lifelogging, and mirror world presented by ASF.

The study presented the world types, but the procedures or methods for designing theses worlds need to be investigated. In order to overcome the limitations of the study, there is a need to examine the design methodology for how the metaverse world is developed into the five world types. The procedures necessary for world design need to be examined by analyzing the existing gamification development methodology or design framework. Real-world development and verification will also be required.

Three types of metaverse were presented by the ASF in addition to the virtual worlds. Out of these, AR is already widely used in education, but most of the AR contents used for education do not reflect the characteristics of the metaverse. Further research is needed to apply lifelogging or mirror world to education. Further research on the applicability of these three types to education from the metaverse perspective needs to be carried out. 


\begin{abstract}
Author Contributions: Conceptualization, S.P.; formal analysis, S.P.; funding acquisition, S.K.; methodology, S.P.; writing—original draft, S.P.; writing—review and editing, S.K. All authors have read and agreed to the published version of the manuscript.
\end{abstract}

Funding: This research was supported by a grant from the National Research Foundation of Korea and funded by the Korean Government (Ministry of Science and ICT; \#2020R1A2B501001801). The research received support from the MSIT (Ministry of Science and ICT), Korea, under the ITRC (Information Technology Research Center) support program (IITP-2021-0-02051) supervised by the IITP (Institute for Information \& Communications Technology Planning \& Evaluation).

Institutional Review Board Statement: Not applicable.

Informed Consent Statement: Not applicable.

Conflicts of Interest: The authors declare no conflict of interest.

\title{
References
}

1. Van der Merwe, D. The Metaverse as Virtual Heterotopia. Available online: https://www.dpublication.com/wp-content/ uploads/2021/10/41-20250.pdf (accessed on 2 December 2021).

2. Park, S.; Min, K.; Kim, S. Differences in learning motivation among Bartle's player types and measures for the delivery of sustainable gameful experiences. Sustainability 2021, 13, 9121. [CrossRef]

3. Deterding, S.; Dixon, D.; Khaled, R.; Nacke, L. From game design elements to gamefulness: Defining "gamification". In Proceedings of the 15th International Academic MindTrek Conference: Envisioning Future Media Environments, New York, NY, USA, 28-30 September 2011; pp. 9-15.

4. Kim, S.; Song, K.; Lockee, B.; Burton, J. Gamification in Learning and Education; Springer: New York, NY, USA, 2018.

5. Huotari, K.; Hamari, J. A Definition for Gamification: Anchoring gamification in the service marketing literature. Electron. Mark. 2017, 27, 21-31. [CrossRef]

6. Eppmann, R.; Bekk, M.; Klein, K. Gameful experience in gamification: Construction and validation of a gameful experience scale [GAMEX]. J. Interact. Mark 2018, 43, 98-115. [CrossRef]

7. The 10 Most Common Video Conferencing Problems Explained. Available online: https://demodesk.com/blog/online-meetings/ most-common-issues-explained (accessed on 1 December 2021).

8. Mukhtar, K.; Javed, K.; Arooj, M.; Sethi, A. Advantages, limitations and recommendations for online learning during COVID-19 pandemic Era. Pak. J. Med. Sci. 2020, 36, S27. [CrossRef] [PubMed]

9. Song, M. The Metaverse Era, Education for Public Officials. Available online: http://www.public25.com/news/articleView. html?idxno=5679 (accessed on 2 December 2021).

10. Kim, J. Design for Experience: Where Technology Meets Design and Strategy; Springer: Berlin/Heidelberg, Germany, 2015.

11. Duan, H.; Li, J.; Fan, S.; Lin, Z.; Wu, X.; Cai, W. Metaverse for social good: A university campus prototype. In Proceedings of the 29th ACM International Conference on Multimedia; Virtual Event, Lisboa, Portugal, 20-24 October 2021; pp. $153-161$.

12. Smart, J.M.; Cascio, J.; Paffendorf, J. Metaverse Road Map; Acceleration Studies Foundation: Ann Arbor, MI, USA, 2007.

13. Borchert, D.M. The Encyclopedia of Philosophy, 2nd ed.; GALE: Farmington Hills, MI, USA, 2006.

14. Dicheva, D.; Dichev, C.; Agre, G.; Angelova, G. Gamification in education: A systematic mapping study. J. Educ. Technol. Soc. 2015, 18, 75-88.

15. Dewey, J. Experience and Education. Educ. Forum 1986, 50, 241-252. [CrossRef]

16. Park, S.; Kim, S. Is sustainable online learning possible with gamification?-The effect of gamified online learning on student learning. Sustainability 2021, 13, 4267. [CrossRef]

17. Guinote, A.; Kim, K.H. Power's Mission: Impact and the quest for goal achievement. Curr. Opin. Psychol. 2020, 33, 177-182. [CrossRef] [PubMed]

18. Jia, Y.; Liu, Y.; Yu, X.; Voida, S. Designing Leaderboards for Gamification: Perceived Differences Based on User Ranking, Application Domain, and Personality Traits. In Proceedings of the 2017 CHI Conference on Human Factors in Computing Systems, New York, NY, USA, 6-11 May 2017; pp. 1949-1960.

19. Majuri, J.; Koivisto, J.; Hamari, J. Available online: https://www.researchgate.net/publication/327438074_Gamification_of_ Education_and_Learning_A_Review_of_Empirical_Literature (accessed on 1 December 2021).

20. Thomas, M.; McGarry, F. Top-down vs. bottom-up process improvement. IEEE Softw. 1994, 11, 12-13. [CrossRef]

21. Wiemker, M.; Elumir, E.; Clare, A. Escape Room Games. Game Based Learn. 2015, 55, 55-75.

22. López-Pernas, S.; Gordillo, A.; Barra, E.; Quemada, J. Examining the use of an educational escape room for teaching programming in a higher education setting. IEEE Access 2019, 7, 31723-31737. [CrossRef]

23. Sahronih, S.; Purwanto, A.; Sumantri, M.S. The effect of interactive learning media on students' science learning outcomes. In Proceedings of the 2019 7th International Conference on Information and Education Technology, Aizu-Wakamatsu, Japan, 29-31 March 2019; pp. 20-24. 